\title{
Groundwater Source Discrimination and Proportion Determination of Mine Inflow Using lon Analyses: A Case Study from the Longmen Coal Mine, Henan Province, China
}

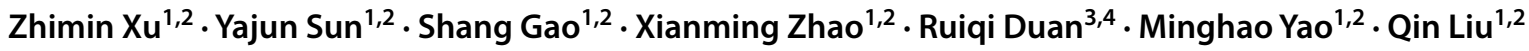

Received: 11 May 2017 / Accepted: 7 January 2018 / Published online: 31 January 2018

(c) The Author(s) 2018. This article is an open access publication

\begin{abstract}
Complex hydrogeological conditions in China's coal mines have contributed to frequent mine water disasters. A simple and effective method to determine water inflow sources and paths is therefore essential. The Longmen Mine, located in Henan Province, in central China was used as a case study. A Piper diagram and cluster analysis were used to screen the characteristic values of 18 water samples from potential aquifers. A comprehensive fuzzy evaluation of the groundwater ions was carried out to determine the main source of the total mine inflow. Then, based on conservation of ionic masses, a matrix function was established to calculate the groundwater recharge composition. Finally, using measured water inflows for the Cambrian limestone aquifer, the calculated and observed results were compared. The results showed that the Carboniferous Taiyuan Formation limestone aquifer (the $\mathrm{L}_{7}$ limestone aquifer) accounts for $60.8 \%$ of the total mine inflow, while the Cambrian limestone and roof sandstone aquifers account for 34.8 and $4.4 \%$ of the inflow, respectively. The normal mine inflow totals about $19,200 \mathrm{~m}^{3} /$ day, of which $6,840 \mathrm{~m}^{3} /$ day is from the Cambrian limestone aquifer. This agrees well with the calculated value of $6,720 \mathrm{~m}^{3} /$ day. Thus, the method is feasible and reliable.
\end{abstract}

Keywords Water quality characteristics - Water characteristic ion - Quantitative analysis - Mine water source identification . Mine water disaster prevention

\section{Introduction}

China is the largest coal producer and coal consumer in the world. In 2016, China's coal production exceeded 3.41 billion tons; currently, coal accounts for $62 \%$ of China's energy resource structure (Xu 2016). However, mine water inrushes

\section{Zhimin Xu}

xuzhimin@cumt.edu.cn

Ruiqi Duan

1500268704@qq.com

1 School of Resources and Geosciences, China University of Mining and Technology, Xuzhou 221116, China

2 National Engineering Research Center of Coal Mine Water Hazard Controlling, Suzhou 234000, China

3 Key Laboratory of Shale Gas and Geoengineering, Institute of Geology and Geophysics, Chinese Academy of Sciences, Beijing 100029, China

4 University of Chinese Academy of Sciences, Beijing 100049, China often occur during mine construction and production in China and accounts for a large proportion of the nation's mine disasters and accidents. Mine water disaster management and prevention is therefore very important.

Hydrogeochemistry has been used to determine water inrush sources and hydraulic connections ( $\mathrm{Li}$ et al. 2016a), and to check the effectiveness of grouting. The water quality characteristics of aquifers are highly variable, and are significantly fuzzy and uncertain. This means that multiple factors are typically needed for comprehensive determinations. Water quality and isotopic analysis have been used to determine water inflow sources, with the assistance of multivariate statistics (Wu et al. 2014). The statistical methods used have included cluster analysis and discrimination analysis, and non-linear analysis methods such as grey relational analysis, fuzzy mathematics, and artificial neural networks (Li et al. 2010, 2015; Pan et al. 2009).

In cluster analysis, water source determination is treated mathematically. A comprehensive classification is then made using mathematical models, and a qualitative and quantitative analysis is conducted, in which the same or 
similar water sources are considered identical types (Xiu et al. 2008). Li et al. (2013) applied multivariate statistical techniques to study groundwater quality in an arid mining area; the sources of the major ions were determined, and the results proved to be an important basis for groundwater quality protection. Trace elements and environmental isotopes have been increasingly used to distinguish between aquifers (Davis and Ashenberg 1988; Gammons et al. 2006). An example of this approach is described by Salem et al. (1980), who studied the groundwater cycle model in western Libya using isotope techniques.

The purpose of this study was to identify mine water sources and quantitatively analyze their composition using comprehensive hydrogeochemical determinations. This approach facilitates important decision-making for mine water disaster control, and quickly and accurately solves the fuzzy and uncertain characteristics of water quality. In addition, the method also can be used at various scales for water resources development, regional water resource evaluations, and environmental assessment.

\section{Hydrogeological Conditions of the Study Area}

The Longmen coal mine is located in Luoyang City, Henan Province (Fig. 1), about $5 \mathrm{~km}$ from the Longmen Grottoes scenic area. The overall elevations in the area are high in the south and east, and low in the north and west.
Cambrian mountains extend over the southern areas, while Quaternary deposits cover the middle and northern areas, with occasional bedrock exposures. The main groundwater sources of mine inflow are the $\mathrm{L}_{7}$ limestone aquifer and the fissured karst Cambrian aquifer.

The main coal seams in the Longmen Mine are located in the Lower Permian Shanxi Formation (Fig. 2). The fractured height over the caved panel (goaf), after mining, is about $58 \mathrm{~m}$. The fractured zone only affects the porous and fractured Shanxi Formation sandstone aquifer in the roof of the coal seam. The aquifer is mainly composed of fine to coarse sandstone, with a thickness of 1.0-21.4 m (averaging $9.55 \mathrm{~m}$ ). The main coal seam is in direct contact with this weakly fissured aquifer, and the damaged floor depth is not more than $20 \mathrm{~m}$. The damaged floor zone in some areas has exposed the $\mathrm{L}_{7}$ limestone aquifer, allowing direct contact with the main coal seam. The aquifer thickness ranges from 3.53 to $15.80 \mathrm{~m}$ and averages $11.52 \mathrm{~m}$. The fissures are not uniformly developed, and the groundwater yields are moderate.

Between the No. $\mathrm{L}_{7}$ limestone and the Cambrian limestone aquifers is the Benxi Formation aquiclude, with a thickness of 2-13.29 $\mathrm{m}$ and an average thickness of $5.25 \mathrm{~m}$. The combined thickness of the Cambrian limestone and the main coal seam is about $45 \mathrm{~m}$, and about $24.61 \mathrm{~m}$ at its thinnest. Without fracturing, there would be no hydraulic connection between the Cambrian limestone aquifer and the panel.

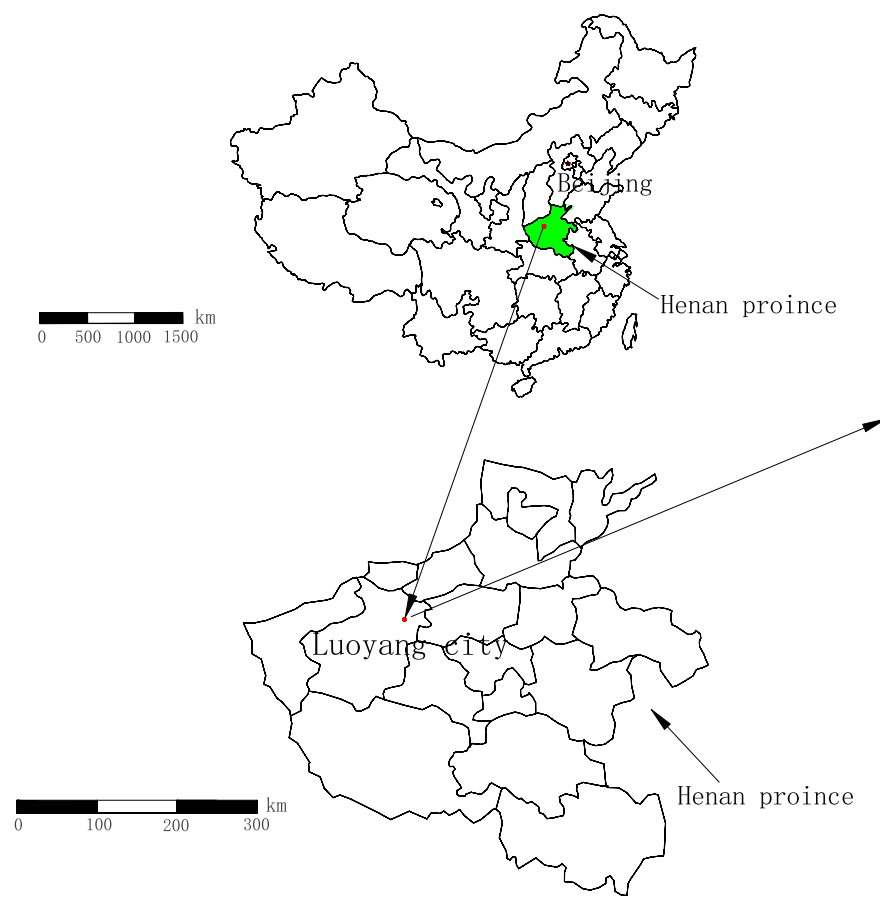

Fig. 1 Location of the Longmen coal mine

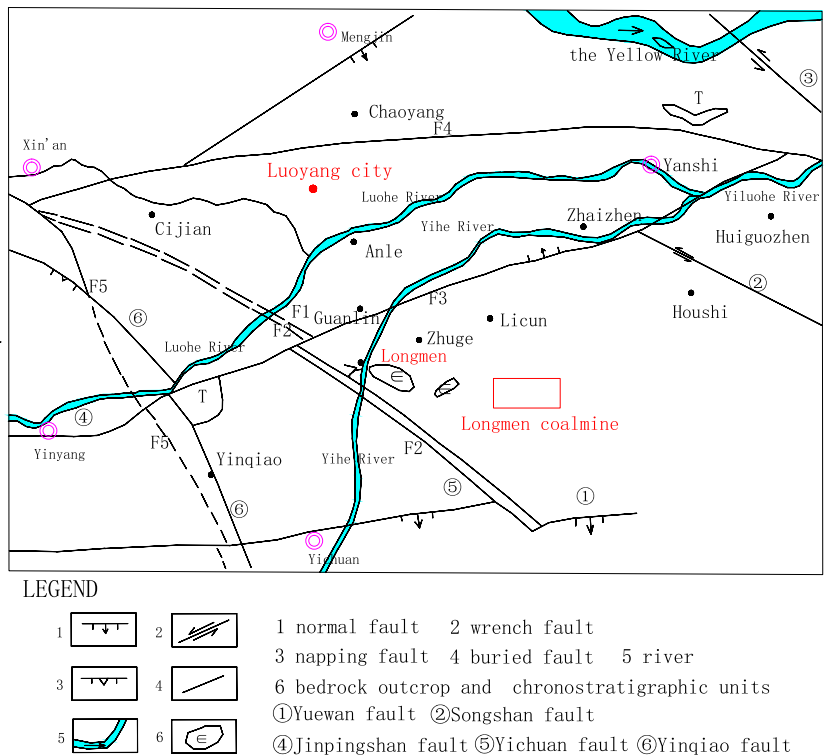


Fig. 2 Histogram of the floor strata of the no. $\mathrm{II}_{1}$ coal seam

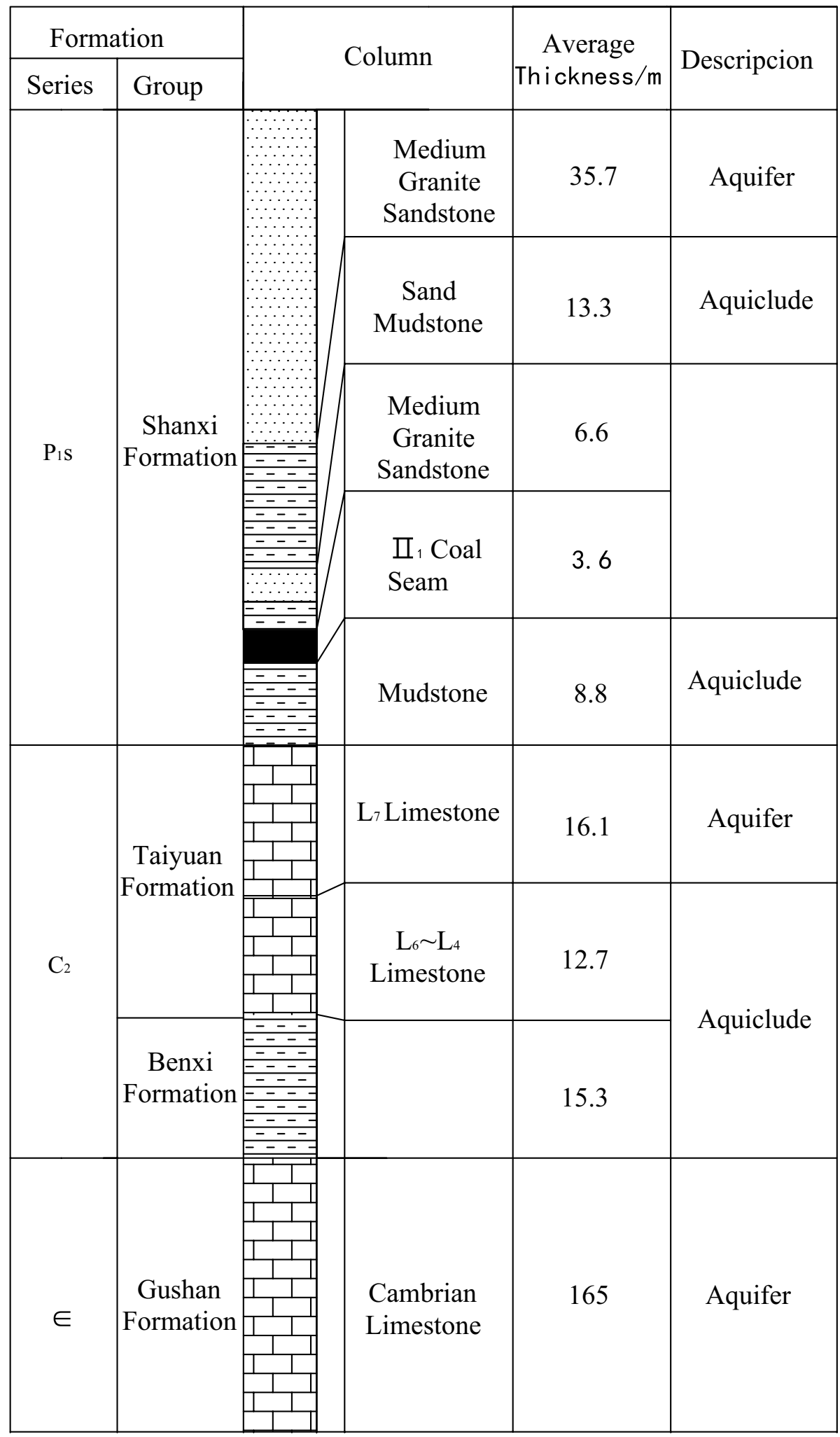

\section{Materials and Methods}

The mine's water quality was used for water source discrimination and quantitative determination. The water quality of 1 mine inflow sample and 17 different potential aquifer samples are shown in Table 1, which includes samples taken from the roof sandstone aquifer, the $\mathrm{L}_{7}$ limestone aquifer, and the Cambrian limestone aquifer. Anomalous water 
Table 1 Ion analysis for water quality (units: $\mathrm{mg} / \mathrm{L}$ )

\begin{tabular}{llllllllll}
\hline $\begin{array}{l}\text { Samples } \\
\text { number }\end{array}$ & Aquifers & $\mathrm{pH}$ & $\mathrm{TDS}$ & $\mathrm{Ca}^{2+}$ & $\mathrm{Mg}^{2+}$ & $\mathrm{K}^{+}+\mathrm{Na}^{+}$ & $\mathrm{Cl}^{-}$ & $\mathrm{SO}_{4}{ }^{--}$ & $\mathrm{HCO}_{3}^{-}$ \\
\hline 1 & No. L limestone & 7.7 & 279 & 70.00 & 22.1 & 11.91 & 0.3 & 23.57 & 302.57 \\
2 & water & 7.5 & 336 & 66.13 & 27.97 & 19.69 & 7.8 & 48.03 & 319.73 \\
3 & & 7.3 & 310 & 75.35 & 17.02 & 20.26 & 10.64 & 34.58 & 305.09 \\
4 & & 7.5 & 318 & 74.15 & 25.54 & 15.18 & 25.24 & 7.2 & 341.59 \\
5 & & 7.45 & 288 & 53.31 & 31.49 & 20.93 & 6.03 & 46.59 & 259.23 \\
6 & & 6.7 & 287 & 76.95 & 20.77 & 14.7 & 10.64 & 23.5 & 300.56 \\
7 & Roof & 6.8 & 370 & 40.2 & 23.91 & 15.29 & 18.37 & 59.1 & 269.7 \\
8 & sandstone water & 7.3 & 341 & 62.52 & 26.51 & 31.72 & 18.44 & 54.58 & 290.72 \\
9 & & 9.9 & 262 & 12.02 & 10.7 & 76.87 & 26.24 & 56.5 & 147.99 \\
10 & & 7.2 & 345 & 64.13 & 28.45 & 26.15 & 21.27 & 61.13 & 279.5 \\
11 & & 7.5 & 279 & 60.12 & 30.28 & 5.06 & 19.14 & 57.77 & 292.79 \\
12 & Cambrian limestone water & 8.5 & 217 & 20.04 & 10.7 & 46.41 & 52.83 & 26.9 & 80.14 \\
13 & & 7.3 & 404 & 71.44 & 25.86 & 26.21 & 10.64 & 58.1 & 305.47 \\
14 & & 7.4 & 295 & 70.14 & 25.9 & 8.51 & 9.66 & 15.85 & 329.4 \\
15 & & 7.25 & 322 & 70.14 & 26.14 & 14.95 & 11.83 & 32.18 & 333.29 \\
16 & & 7.5 & 273 & 59.52 & 31.98 & 0.69 & 10.6 & 21.61 & 297.68 \\
17 & & 8.1 & 291 & 68.14 & 20.67 & 14.72 & 12.06 & 28.82 & 292.89 \\
18 & Mine inflow & 7.1 & 292 & 60.92 & 25.27 & 15.33 & 8.86 & 32.95 & 295.58 \\
\hline
\end{tabular}

sampling points and their data were excluded by cluster analysis using Piper tri-linear diagrams. Then fuzzy comprehensive evaluation and ion conservation principles were used to analyze the water source and the quantitative composition of the mine inflow.

\section{The Methods for Excluding Exception Points}

The Piper tri-linear diagram (Piper 1944) is one of the most useful graphical representations in groundwater quality studies. The graphs are expressed as a percentage of the milligram equivalent of the three major groups of cations $(\mathrm{Ca}$, $\mathrm{Mg}$, and $\mathrm{Na}+\mathrm{K})$ and anions $\left(\mathrm{Cl}, \mathrm{SO}_{4}\right.$, and $\left.\mathrm{HCO}_{3}+\mathrm{CO}_{3}\right)$. Each figure consists of three parts: in the lower left and lower right are two isosceles triangles, and in the middle of the upper part is a diamond-shaped domain (Fig. 3), and each side of the length of the field extends from 0 to $100 \%$. In the lower left of the isosceles triangle, the percentage of the three major cationic reaction values is represented by a single point in tri-linear coordinates ( $\mathrm{Li}$ et al. 2016b, c). In the lower right of the isosceles triangle, anions are expressed the same way. Thus, the graph represents the chemical characteristics of groundwater using relative rather than absolute chemical composition concentrations ( $\mathrm{Li}$ et al. 2016d).

Cluster analysis, also known as group analysis, is a multivariate statistical method for studying the classification of samples or indicators, and is useful when there are a large number of samples that require a reasonable

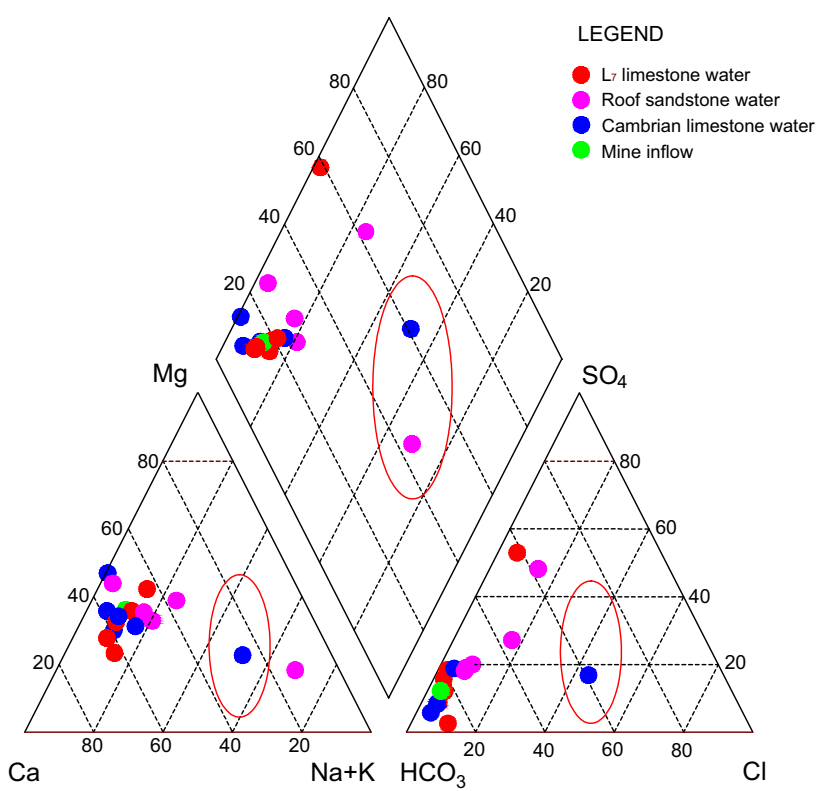

Fig. 3 Piper diagram of water samples from different aquifers

classification of their characteristics, in the absence of prior knowledge. A water sample can be considered as a point in p-dimensional space, and close points in that space can be classified as a class, and points at greater distances classified as different categories. 


\section{Analysis of Water Source and Quantitative Composition}

Fuzzy comprehensive evaluation is used to assess the membership status of multi-factor and multi-level complex problems, and has been widely used in mine inflow source discrimination. A mathematical model for fuzzy comprehensive evaluation was established using hydrodynamic analysis data for the mine aquifers and mine inflow data. We used the biased weighting method to determine the weight of representative factors, while the expert reasoning method was used to determine the membership degree, and to make a fuzzy comprehensive judgment of the mine inflow source when there were a number of aquifers that could lead to water inrush (Ben et al. 2005; Gao 2012; Liu et al. 2015; Song 1999; Xia et al. 2002; Yu et al. 2007).

The law of conservation of mass includes atomic conservation, conservation of charge, and conservation of elements. In element conservation, the mass of an element remains constant before and after a chemical reaction. Conservation of water ions is an extension of the conservation of elements.

\section{Results and Discussion}

\section{Exclusion of Exception Points}

A Piper tri-linear diagram (Fig. 3), compiled from the data in Table 1, shows the mine water plots for the water samples of the three aquifers, and confirms that the mine water is a combination of the three different sources. The water quality of samples 9 (from the roof sandstone aquifer) and 12 (from the Cambrian limestone aquifer) are different from the other samples, as shown in the red oval area in Figs. 3 and 4. Therefore, these two samples were considered anomalies and excluded from further analysis.

The cluster analysis results were consistent with the Piper tri-linear diagram results in terms of excluding these two samples. The average values of the samples from each aquifer were used to create characteristic ion values for each aquifer (Table 2).

\section{Water Source Discrimination}

The characteristic ions of each aquifer were determined, and used to analyze the source(s) of the mine water inflow. The fuzzy comprehensive evaluation follows three main steps:
Fig. 4 Cluster analysis of water samples (blue-roof sandstone water; red-Cambrian limestone water; green $-\mathrm{L}_{7}$ limestone water)
Table 2 Mine inflow and aquifer water characteristic ion values (unit: $\mathrm{mg} / \mathrm{L}$ )

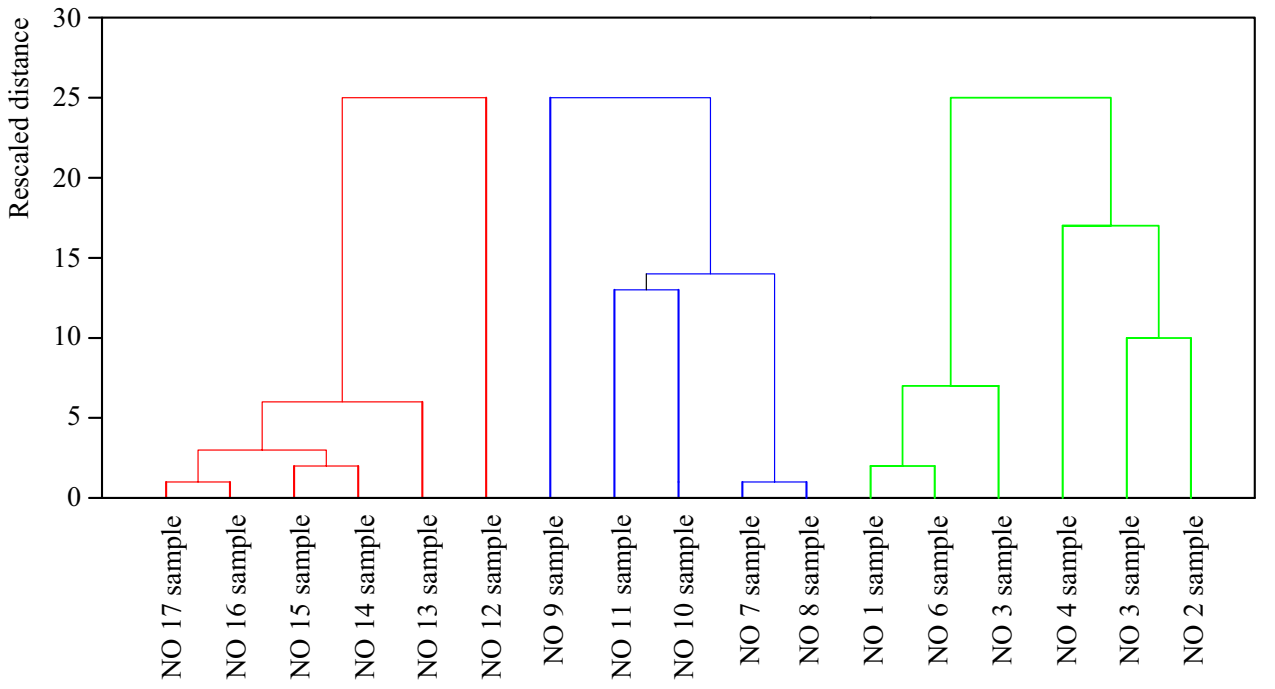

\begin{tabular}{lllllll}
\hline Aquifers & $\mathrm{Ca}^{2+}$ & $\mathrm{Mg}^{2+}$ & $\mathrm{K}^{+}+\mathrm{Na}^{+}$ & $\mathrm{Cl}^{-}$ & $\mathrm{SO}_{4}{ }^{2-}$ & $\mathrm{HCO}_{3}{ }^{-}$ \\
\hline No. $\mathrm{L}_{7}$ limestone water & 68.90 & 22.85 & 16.95 & 6.9 & 32.06 & 300.86 \\
Roof sandstone water & 56.74 & 21.91 & 19.49 & 19.31 & 58.15 & 283.18 \\
Cambrian limestone water & 67.88 & 26.11 & 13.02 & 10.96 & 31.31 & 311.75 \\
Mine inflow & 60.92 & 25.27 & 15.33 & 8.86 & 32.95 & 295.58 \\
\hline
\end{tabular}


1. Establish a factor set: $U=\left\{\mathrm{K}^{+}+\mathrm{Na}^{+}, \mathrm{Ca}^{2+}, \mathrm{Mg}^{2+}\right.$, $\left.\mathrm{Cl}^{-}, \mathrm{SO}_{4}^{2-}, \mathrm{HCO}_{3}^{-}\right\}$

2. Establish an evaluation set: $V=\left\{\mathrm{L}_{7}\right.$ limestone water, roof sandstone water, Cambrian limestone water $\}$. The three aquifers will be referred to as I, II, and III, respectively;

3. Set a weight vector for the methods used to determine the weights: $A=\left\{a_{1}, a_{2}, \ldots, a_{m}\right\}$. Fuzzy comprehensive evaluation can use super weighting or biased weighting. The super-weighting method tends to assign greater weight to positive factors that deviate more than the average, while biased weighting does not consider positive or negative bias, but uses absolute values of deviations from the mean. We used the biased weighting method because it incorporates more factors to allocate weight (Wei 2001).

$a_{i}=\frac{\frac{\left|S_{i}-U_{i}\right|}{U_{i}}}{\sum_{x=1}^{m} \frac{\left|S_{x}-U_{x}\right|}{U_{x}}} \quad\left(U_{\mathrm{i}}=\frac{U_{i 1}+U_{i 2}+U_{i 3}}{3}, U_{x}=\frac{U_{x 1}+U_{x 2}+U_{x 3}}{3}\right)$

where $a_{i}$ is the weight of the evaluation factors of the $i$-th water sample, $\mathrm{S}_{i j}\left(\mathrm{~S}_{x j}\right)$ is the measured value of the $\mathrm{i}(\mathrm{x})$ factor of the water sample, $U_{i 1}, U_{i 2}$, and $U_{i 3}\left(U_{x 1}, U_{x 2}, U_{x 3}\right)$ are the I evaluation factors in the standard value of each aquifer, respectively. $U_{i}\left(U_{x}\right)$ is the average of the $\mathrm{i}(\mathrm{x})$ evaluation factors for all aquifers, and $m$ is the number of evaluation factors.

The weights of the evaluation factors determined by the biased weighting method are shown in Table 3. Membership degree was determined by the expert reasoning method, and the membership function of a trapezoidal fuzzy distribution was adopted. This is not restricted by the ion species and is suitable for mines in different environments. Taking $\mathrm{K}^{+}+\mathrm{Na}^{+}$ as an example to analyze the membership function:

$r_{1}=\left\{\begin{array}{cc}0 & (x \leq 13.02) \\ \frac{x-13.02}{16.95-13.02} & (13.02<x<16.95) \\ \frac{19.49-x}{19.49-16.95} & (16.95 \leq x<19.49) \\ 0 & (x \geq 19.49)\end{array}\right.$

$r_{3}= \begin{cases}0 & (x \leq 16.95) \\ \frac{x-16.95}{19.49-16.95} & (16.95<x<19.49) \\ 1 & (x \geq 19.49)\end{cases}$ $r_{3}= \begin{cases}1 & (x \leq 13.02) \\ \frac{16.95-x}{16.95-13.02} & (13.02<x<16.95) \\ 0 & (x \geq 16.95)\end{cases}$

where $r_{1}(x), r_{2}(x)$, and $r_{3}(x)$ are the membership functions of $\mathrm{K}^{+}+\mathrm{Na}^{+}$for aquifers I, II, and III, respectively. The calculated $\mathrm{K}^{+}+\mathrm{Na}^{+}$as an influencing factor for evaluation of $R_{\mathrm{Na}^{+}+K^{+}}=(0.588,0,0.412)$. The influencing factors for $\mathrm{Ca}^{2+}, \mathrm{Mg}^{2+}, \mathrm{HCO}^{3-}, \mathrm{SO}_{4}{ }^{2-}$, and $\mathrm{Cl}-$ were then calculated and for each, a fuzzy evaluation matrix $\mathrm{R}$ was obtained.

$R=\left[\begin{array}{ccc}0 & 0.625 & 0.375 \\ 0.258 & 0 & 0.742 \\ 0.588 & 0 & 0.412 \\ 0.701 & 0.299 & 0 \\ 0.966 & 0.034 & 0 \\ 0.517 & 0 & 0.483\end{array}\right]$

The evaluation results of the mine water samples are calculated as:

$B=A R=(0.582,0.065,0.353)$

The fuzzy comprehensive evaluation method can be used to deal with uncertain and random factors such as the main inflow sources of mine water. According to our results, the impact of the aquifers on the mine inflow is 0.582 for the $\mathrm{L}_{7}$ limestone aquifer, 0.353 for the Cambrian limestone aquifer, and 0.065 for the roof sandstone aquifer. By applying the principle of maximum membership, we determined that the main water source for the mine inflow in the Longmen Mine is the $\mathrm{L}_{7}$ limestone aquifer.

The $\mathrm{L}_{7}$ limestone aquifer is $2.9-19.4 \mathrm{~m}$ below the no. $\mathrm{II}_{1}$ coal seam. Under normal circumstances, the floor-damaged zone extends to depths of about $5.65-18.38 \mathrm{~m}$, and will therefore, in some areas, expose the $\mathrm{L}_{7}$ limestone aquifer, resulting in inflow from this aquifer. This is consistent with the fuzzy discrimination results.

\section{Proportion Determination}

The principle of conservation of elements can be applied to the ionic composition of mixed solutions, so the composition and

Table 3 Evauation factor weight

\begin{tabular}{lllllll}
\hline Evaluation factors & $\mathrm{Ca}^{2+}$ & $\mathrm{Mg}^{2+}$ & $\mathrm{K}^{+}+\mathrm{Na}^{+}$ & $\mathrm{HCO}_{3^{-}}$ & $\mathrm{SO}_{4}^{2-}$ & $\mathrm{Cl}^{-}$ \\
\hline Weights & 0.082 & 0.103 & 0.104 & 0.015 & 0.276 & 0.421 \\
\hline
\end{tabular}


content of the elements are the same after the water from the three aquifers is mixed to form the mine water. However, $\mathrm{Ca}^{2+}$, $\mathrm{Mg}^{2+}$, and $\mathrm{HCO}_{3}{ }^{-}+\mathrm{CO}_{3}{ }^{2-}$ are susceptible to the influence of other ions and $\mathrm{pH}$, while $\mathrm{K}^{+}+\mathrm{Na}^{+}, \mathrm{SO}_{4}{ }^{2-}$, and $\mathrm{Cl}^{-}$are less affected by other ions. The overall ionic content of the mixed solution remains unchanged.

The mine inflow proportions were designated as: $\mathrm{x}$ is water from the $\mathrm{L}_{7}$ limestone aquifer, $\mathrm{y}$ is from the roof sandstone aquifer, and $\mathrm{z}$ is from the Cambrian limestone aquifer. Migrating groundwater often undergoes processes such as filtration, enrichment, adsorption, and ion exchange (Li et al. 2010; Zheng et al. 1998). Ion exchange can lead to $\mathrm{Ca}^{2+}$ and $\mathrm{Mg}^{2+}$ being exchanged for $\mathrm{K}^{+}$and $\mathrm{Na}^{+}$; therefore, we used a combination of $\mathrm{Cl}^{-}$and $\mathrm{SO}_{4}{ }^{2-}$ to calculate the relative proportion of the aquifer sources in the inflow:

$\left[\begin{array}{ccc}6.9 & 19.3 & 11.0 \\ 32.1 & 58.2 & 31.3 \\ 1 & 1 & 1\end{array}\right]\left[\begin{array}{l}x \\ y \\ z\end{array}\right]=\left[\begin{array}{c}8.9 \\ 33.0 \\ 1\end{array}\right]$

Solving equations (6) yields $\mathrm{x}=0.608, \mathrm{y}=0.044$, and $\mathrm{z}=0.348$. This means that the $\mathrm{L}_{7}$ limestone aquifer accounts for $60.8 \%$ of the total mine inflow, while the Cambrian limestone and roof sandstone aquifers account for $34.8 \%$ and $4.4 \%$ of the inflow, respectively. The total mine inflow is normally about $19,200 \mathrm{~m}^{3} /$ day, of which $6,840 \mathrm{~m}^{3} /$ day is from the Cambrian limestone aquifer. This agrees well with the calculated value of $6,720 \mathrm{~m}^{3} /$ day. The Cambrian limestone inflow is essentially the residual water of the Cambrian limestone inrush area.

Experience has confirmed that although the damaged floor zoneextended to large areas of the $\mathrm{L}_{7}$ limestone aquifer, mine water inflow did not significantly increase. However, even though the $\mathrm{L}_{7}$ limestone aquifer is not water-rich, the $\mathrm{L}_{7}$ limestone aquifer is still the largest total mine inflow source. Thus, according to the quantitative analysis, attention should focus on the $\mathrm{L}_{7}$ and Cambrian limestone aquifers. Reliable and effective floor grouting and mine plan modifications can be used to safely mine this deposit.

\section{Conclusions}

1. Determination of the mine inflow sources is affected by a variety of factors and can be difficult to accurately determine during the mining process. However, tsuch determinations are important for mine water disaster control. Thus, there is a need for a reliable method to address this issue.

2. In this paper, the water characteristics of a mine's inflow were determined by using a Piper tri-linear diagram and cluster analysis. The water source and quantitative composition were analyzed using fuzzy comprehensive evaluation and the law of conservation of mass.

3. Mine water disasters are a major technical challenge. In this paper, ion characteristics, biased weighting, and ion conservation were used to accurately identify the sources of mine water inflow. The resulting information can be used to prevent and reduce adverse groundwater impacts in the Longmen Mine. Also, this approach can be used for further development of quick-response inrush source determination devices.

Acknowledgements This research was financially supported by the National Key Research and Development Program of China (2017YFC0804101), the National Natural Science Foundation of China (41502282), the National Basic Research Program of China (2013CB227901), and the Priority Academic Program Development (PAPD) of Jiangsu Higher Education Institution.

Open Access This article is distributed under the terms of the Creative Commons Attribution 4.0 International License (http://creativeco mmons.org/licenses/by/4.0/), which permits unrestricted use, distribution, and reproduction in any medium, provided you give appropriate credit to the original author(s) and the source, provide a link to the Creative Commons license, and indicate if changes were made.

\section{References}

Ben X, Guo Y, Ren Y, Li H (2005) Discussion on weighting determination in comprehensive fuzzy water source judgment application. Coal Geol Chin 5:58-60 + 70 (in Chinese)

Davis A, Ashenberg D(1988) The aqueous geochemistry of the Berkeley Pit, Butte, Montana, USA. Appl Geochem 44:23-36

Gammons CH, Poulson SR, Pellicori DA, Reed PJ, Roeslera AJ, Petrescuetc EM (2006) The hydrogen and oxygen isotopic composition of precipitation, evaporated mine water, and river water in Montana, USA. J Hydrol 328:319-330

Gao W (2012) Application of fuzzy comprehensive evaluation method of entropy weight in water source identification of mine water bursting. Min Safe Environ Protect 2:22-24 (in Chinese)

Li Y, Sun Y, Xu Z, Zhang G, Liu Y, Ding J (2010) Analysis of composition of mine inflow from complicated multi-aquifer affecting safety production in coal mines. J Min Safe Eng 3:433-437 (in Chinese)

Li P, Qian H, Wu J, Zhang Y, Zhang H (2013) Major ion chemistry of shallow groundwater in the Dongsheng coalfield, Ordos basin, China. Mine Water Environ 32(3):195-206

Li F, Zhang F, Niu Z, Li Y, Cui J, Su B (2015) Analysis and judgment of water source of drinking water by set - intersection method. Min Safe Environ Protect 5:99-102 (in Chinese)

Li P, Wu J, Qian H (2016a) Preliminary assessment of hydraulic connectivity between river water and shallow groundwater and estimation of their transfer rate during dry season in the Shidi River, China. Environ Earth Sci 75(2):99

Li P, Wu J, Qian H, Zhang Y, Yang N, Jing L, Yu P (2016b) Hydrogeochemical characterization of groundwater in and around a wastewater irrigated forest in the southeastern edge of the Tengger Desert, northwest China. Expos Health 8(3):331-348 
Li P, Zhang Y, Yang N, Jing L, Yu P (2016c) Major ion chemistry and quality assessment of groundwater in and around a mountainous tourist town of China. Expos Health 8(2):239-252

Li P, Wu J, Qian H (2016d) Hydrochemical appraisal of groundwater quality for drinking and irrigation purposes and the major influencing factors: a case study in and around Hua County, China. Arab J Geosci 9(1):15. https://doi.org/10.1007/s1251 7-015-2059-1

Liu J, Wang Ji-ren, Liu Y, Wu H, Zhou B (2015) Hydrochemistry analysis based on the source determination of coal mine waterbursts. J Safe Environ 1:31-35 (in Chinese)

Pan G, Wang S, Sun X, Fan S (2009) Application of isotope technique in judging mine water bursting water. Min Safe Environ Protect $1: 32-34+90$ (in Chinese)

Piper AM (1944) A graphical procedure in the geochemical interpretation of water analysis. Am Geophys Union Trans 25:914-928

Salem O, Visser JH, Dray M, Gonfiantini R (1980) Groundwater flow patterns in the western Libyan Arab Jamahiriya evaluated from isotopic data. Investigations with Isotope Techniques, International Atomic Energy Agency, Arid-Zone Hydrology, Vienna, pp165-179

Song X (1999) Fuzzy Mathematics Principles and Methods. China Univ of Mining Press, Xuzhou (in Chinese)
Wei J, Li Y, Zheng J, Cheng L, Zhang Y, Zhou H (2001) The application of BP neural network to the evaluation of wellhead field influence. Acta Geosci Sinica 22(3):283-288 (in Chinese)

Wu J, Li P, Qian H, Duan Z, Zhang X (2014) Using correlation and multivariate statistical analysis to identify hydrogeochemical processes affecting the major ion chemistry of waters: case study in Laoheba phosphorite mine in Sichuan, China. Arab J Geosci 7(10):3973-3982

Xia X, Zhang H, Yang W (2002) Using fuzzy comprehensive evaluation method to determine water bursting water in Caozhuang coal mine. West Explora Eng 4:54-56 (in Chinese)

Xiu Z, Wei Y, Li B, Zhang L (2008) Application of cluster analysis in discrimination of mine water source. Saf Coal Min 39(2):47-49 (in Chinese)

Xu L (2016) China Energy Statistical Yearbook 2016. China Statistics Press, Beijing (in Chinese)

Yu K, Yang Y, Zhang C (2007) Application of fuzzy comprehensive evaluation method in judging the water inrush from mine. Metal Mine 3: 47-50 (in Chinese)

Zheng S, Chen J, Liu H, Hu Y, Sun Y (1998) Special Hydrogeology. China Univ of Mining and Technology Press, Xuzhou (in Chinese) 